\title{
ELLIPSOMETRIC DATA OF CADMIUM OXIDE LAYERS FORMED ANODICALLY IN SODIUM HYDROXIDE SOLUTIONS
}

\author{
J. O. Zerbino, S. B. Saidman, J. R. Vilche and A. J. Arvia \\ Instituto de Investigaciones Fisicoquimicas Teóricas y Aplicadas (INIFTA), Facultad de Ciencias \\ Exactas, Universidad Nacional de La Plata, Sucursal 4, Casilla de Correo 16, (1900) La Plata, \\ Argentina
}

(Received 9 January 1989)

The voltammetric formation of cadmium oxide layers in alkaline solutions is related to the appearance of two peaks which were assigned to successive reactions occurring within well defined potential ranges $[1,2]$. It is interesting to attempt to follow the electroformation and electroreduction of the cadmium oxide layers by means of ellipsometry and to combine the latter to voltammetry in order to provide throughout the correlation of data a way to achieve a better knowledge of the ellipsometric parameters of $\mathrm{Cd}(\mathrm{OH})_{2}$ and $\mathrm{CdO}$ layers [3-6] in contact with the alkaline solution.

Runs were made with an electrochemical cell properly mounted in a Rudolph research type ellipsometer at $546.1 \mathrm{~nm}$ and room temperature. The mirror polished $\mathrm{Cd}$ electrode was made from polycrystalline (Specpure) cadmium, and the electrolyte was $\mathrm{NaOH}$ in the 0.01 to $1 \mathrm{M}$ concentration range. Potentials were measured against a reversible hydrogen electrode in the same solution and referred to in the text to the $n$ he scale. The ellipsometric readings ( $P$ and $A)$ were made under extinction conditions at different potentials and potential holding times.

The ellipsometric data for the anodised $\mathrm{Cd}$ electrode show a relatively large decrease in $\Delta$ and a slight increase in $\psi$. Changes in $\Delta$ are mainly related to the accumulation of $\mathrm{Cd}(\mathrm{OH})_{2}$ and $\mathrm{CdO}$. Otherwise, the value of $\Delta$ after the anodic layer electroreduction exceeds in $\mathrm{ca} 2^{\circ}$ that initially obtained for freshly polished $\mathrm{Cd}$. The accumulation of anodic product during cycling is mainly responsible for the change in $\Delta$. A second contribution in the change of $\Delta$ can be assigned to the roughness of the electroreduced $\mathrm{Cd}$ overlayer.

The change of $\psi$ during the formation of anodic products at low potential sweep rates becomes greater than at high potential sweep rates as it should be expected from the amount of product accumulated at different potential sweep rates. Measurements performed by including short potential scans and current interruption periods at different potentials indicate that the ellipsometric response follows the electrochemical scan but with a clear hysteresis presumably due to changes in the properties of the anodic layer produced under open circuit.
The experimental results were compared to the parametric relations resulting from different models for the anodic layer. On the basis of a single homogeneous layer model, the best fitting of the experimental results can be obtained for the initial oxidation stage with $\bar{n}=1.55-i 0.005$, and at high anodic potentials with $\bar{n}=2.6-i 0.23$. These figures are consistent with a hydrous structure for the anodic layer.

In agreement with voltammetric data, the ellipsometric results confirm that both the electroformation of the anodic layer as well as its electroreduction involve two distinguishable stages. Each stage is related either to a hydrous $\mathrm{Cd}(\mathrm{OH})_{2}$ or hydrous $\mathrm{CdO}$ layer as mainly participants in the reaction.

Under open circuit the ellipsometric parameters for the anodic reaction shift in the direction expected for a decrease in layer thickness. This fact can be associated with ageing effects resulting from a slight decrease in the water content of the anodic layer.

The ellipsometric parameters of the electroreduced Cd overlayer are different from those of the initial $\mathrm{Cd}$ surface. This fact is accompanied by an enhancement of the HER and it is presumably related to the development of some microporosity.

Acknowledgement - This work was financially supported by the Consejo Nacional de Investigaciones Cientificas y Tecnicas and the Comision de Investigaciones Cientificas de la Provincia de Buenos Aires.

\section{REFERENCES}

1. R. Barnard, J. appl. Electrochem. 11, 217 (1981).

2. S. B. Saidman, J. R. Vilche and A. J. Arvia, Electrochim. Acta 32, 395 (1987).

3. A. P. Lenhan and D. M. Treherne, Proc. phys. Soc. 83, 1059 (1964).

4. R. H. W. Graves and A. P. Lenhan, J. Opt. Soc. Am. 58, 884 (1968).

5. M. Gauch and G. Quentel, Surf. Sci. 108, 617 (1981).

6. H. Finkenrath and M. von Ortenberg, $Z$. Angew. Phys. 23, 323 (1967). 